\title{
Emotional variability during mother-adolescent conflict interactions: Longitudinal links to adolescent disclosure and maternal control
}

\author{
Daniëlle Van der Giessen ${ }^{a, *}$, Susan Branje ${ }^{b}$, Loes Keijsers ${ }^{b}$, Pol A.C. Van Lier ${ }^{c}$, \\ Hans M. Koot ${ }^{\mathrm{c}}$, Wim Meeus ${ }^{\mathrm{b}, \mathrm{d}}$ \\ a Department of Child Development and Education, University of Amsterdam, P.O. Box 94208, 1090 GE Amsterdam, The Netherlands \\ ${ }^{\mathrm{b}}$ Research Centre Adolescent Development, Utrecht University, P.O. Box 80140, 3508 TC Utrecht, The Netherlands \\ ${ }^{\mathrm{c}}$ Faculty of Psychology and Education, VU University Amsterdam, Van der Boechorstraat 1, 1081 BT Amsterdam, The Netherlands \\ ${ }^{\mathrm{d}}$ Developmental Psychology, Tilburg University, P.O. Box 90153, 5000 LE Tilburg, The Netherlands
}

Keywords:

Emotional variability

Mother-adolescent interactions

Conflicts

Adolescent disclosure

Maternal control

\begin{abstract}
A B S T R A C T
The aim of this study was to examine relations of emotional variability during motheradolescent conflict interactions in early adolescence with adolescent disclosure and maternal control in early and late adolescence. Data were used from 92 mother-adolescent dyads ( $M$ age $\mathrm{T} 1=13.05 ; 65.20 \%$ boys) that were videotaped at $\mathrm{T} 1$ while discussing a conflict. Emotional variability was derived from these conflict interactions. Mothers also completed questionnaires at the start of the study (T1) and five years later (T6) on adolescent disclosure and maternal control. Path analysis showed that more emotional variability during conflict interactions in early adolescence was associated with higher levels of adolescent disclosure in early adolescence and with relative decreases in maternal control from early to late adolescence. More emotional variability of mother-adolescent dyads serves an important function in adaptively dealing with relational challenges that arise during adolescence.
\end{abstract}

(C) 2013 The Foundation for Professionals in Services for Adolescents. Published by Elsevier Ltd. All rights reserved.

Adolescence is a developmental phase that is marked by profound changes in mother-adolescent relationships. Motheradolescent dyads need to find a new balance between adolescents' autonomy and privacy on the one hand and maternal control and access to information on the other hand. Across adolescence, mother-adolescent relationships tend to change from more hierarchical relationships in early adolescence to more egalitarian relationships by late adolescence (Laursen \& Collins, 2009; Smetana, 2011). Conflict interactions in early adolescence are thought to play an important role in reorganizing mother-adolescent relationships towards more horizontality (Adams \& Laursen, 2007; Branje, Laursen, \& Collins, 2012). Nevertheless, there is still a lack of longitudinal evidence to empirically support this claim. To understand how motheradolescent dyads attain a more egalitarian relationship, the current study examines the role of emotional processes during mother-adolescent conflict interactions in early adolescence.

\footnotetext{
* Corresponding author.

E-mail addresses: D.vandergiessen@uva.nl (D. Van der Giessen), S.branje@uu.nl (S. Branje), L.Keijsers@uu.nl (L. Keijsers), pac.van.lier@vu.nl (P.A.C. Van Lier), J.M.Koot@vu.nl (H.M. Koot),W.meeus@uu.nl (W. Meeus).
} 


\section{Developmental changes during adolescence}

Adolescence is characterized by a striving for greater autonomy. As adolescents try to assert more control and independence, they begin to re-evaluate the hierarchy of family roles (Zimmer-Gembeck \& Collins, 2006). Adolescents increasingly consider pieces of information about their daily life and activities as private and personal and consider it less legitimate for mothers to exert control over things. Although mothers gradually release their control over the course of adolescence, they continue to experience that some of these issues still fall under their jurisdiction (Keijsers \& Poulin, 2013; Petronio, 2002). These relational changes can go together with temporary increases in emotional turmoil and conflict intensity (Collins \& Steinberg, 2006; Laursen, Coy, \& Collins, 1998). Conflict interactions offer important experiences for mothers and adolescents to express, modulate, and regulate different types of emotions together in response to a difficult emotional conversation topic. Thereby conflict interactions represent an important context where adolescents' emotion regulation development takes place (Morris, Silk, Steinberg, Myers, \& Robinson, 2007). Mother-adolescent dyads eventually need to find a way of communicating during these conflicts that allows for disagreement, negative emotions, and autonomy to occur and at the same time enhances relatedness and problem solving (Bosma et al., 1996; Laursen \& Collins, 2009). Thus, although conflict interactions can be unpleasant, they are considered to be a means of recognizing and resolving discordant expectations regarding autonomy and control. As such, mother-adolescent conflict interactions are thought to enable mothers and adolescents to develop a more egalitarian relationship (Adams \& Laursen, 2007). The purpose of the current study was to take initial steps in examining the role of emotional variability during mother-adolescent conflict interactions for dealing with relational challenges regarding disclosure and control.

\section{The function of emotional variability in conflict interactions}

An aspect of mother-adolescent conflict interactions that has gained increased attention is emotional variability, which reflects the ability of mother-adolescent dyads to flexibly switch between dyadic emotional states from moment-to-moment during conflict interactions (Hollenstein, 2012). Mother-adolescent dyads with higher levels of emotional variability tend to express a wide range of positive and negative emotions and are able to flexibly adapt these emotions according to interpersonal demands. In contrast, mother-adolescent dyads with lower levels of emotional variability have a tendency to get stuck in certain emotions (either positive or negative) during conflicts. From a dynamic systems approach (Fogel, 1993; Thelen \& Smith, 1994), more emotional variability during conflict interactions in early adolescence is thought to allow dyads to reorganize interaction patterns. That is, mother-adolescent dyads that show relatively high levels of emotional variability during conflict interactions are expected to adequately express their thoughts and emotions, to put across their point of view clearly, and to adjust discrepant perceptions accordingly. These dyads are expected to adequately deal with differences in opinions. In contrast, mother-adolescent dyads with low levels of emotional variability that show a tendency to get stuck in emotions during conflict interactions, even if they get stuck in neutral or positive emotions, might not be able to solve their conflicts, because these dyads may not provide a supportive and secure context to discuss different point of views and discordant emotions (Branje, 2008; Van der Giessen, Branje, Frijns, \& Meeus, 2013).

Empirical evidence has shown that more emotional variability in early adolescence was associated with indicators of adaptive relationship reorganization. Higher levels of emotional variability were associated with moderate levels of perceived conflict frequency (Lichtwarck-Aschoff, Kunnen, \& van Geert, 2009), with a realignment of levels of perceived dominance, criticism, and open communications in mother-adolescent relationships (Branje, 2008), and with a decrease in perceived conflict frequency and an increase in perceived autonomy support over time (Van der Giessen et al., 2013). Taken together, both theory and research suggest that more emotional variability during mother-adolescent conflict interactions is helpful in dealing with various relational challenges that arise during adolescence, and serves an important function in adaptively realigning relationships towards a more equal and horizontal nature.

\section{Emotional variability: links with adolescent disclosure and maternal control}

Emotional variability in mother-adolescent conflict interactions could also play a role in dealing with relational challenges that arise with respect to adolescent disclosure and maternal control. Being able to express your thoughts, feelings, and emotions during conflict interactions, indicative of high emotional variability, is considered to be related to more open communication patterns, which might facilitate adolescent disclosure and could reduce maternal control (e.g., Adams \& Laursen, 2007; Butler, 2011). First, adolescent disclosure reflects in the current study the extent to which mothers perceive that adolescents voluntarily and spontaneously reveal information about friends, activities, and whereabouts. Spontaneous disclosures of adolescents are thought to enhance mutual trust and understanding, and might also create a more egalitarian mother-adolescent relationship (Branje et al., 2012). One of the main reasons why adolescents refrain from disclosure is their concern about mothers' potentially negative responses about the content of their disclosure (Marshall, Tilton-Weaver, \& Bosdet, 2005; Tilton-Weaver et al., 2010). This implies that adolescents feel safer to disclose to their mothers in a context where their emotions, both positive and negative, are likely to be accepted. More emotional variability during conflict interactions might be indicative of such a safe and supportive context characterized by more open communication, because more emotionally variable mothers and adolescents are thought to be able to freely express different types of emotions. More emotional variability in early adolescence might therefore be related to more adolescent disclosure both concurrently and over time. 
Second, maternal control denotes in the current study the extent to which mothers perceive themselves as controlling their adolescent child's activities and friendship. To match adolescents' autonomy needs, mothers generally tend to exert less control over time (Keijsers \& Poulin, 2013). As mother-adolescent conflict is considered to be a means of recognizing and resolving discordant expectations regarding control and autonomy, it can provide an important context for negotiating maternal authority towards adolescents (Hawk, Hale, Raaijmakers, \& Meeus, 2008; Petronio, 2002). When mother-adolescent dyads express different emotions more flexibly and easily during conflict interactions, these dyads might talk about discordant expectations more thoroughly as they are searching for new patterns of behaviors that match maturing autonomy needs of adolescents. In this way, more emotional variability during conflict interactions in early adolescence may represent an important part of the process by which mothers and adolescents adequately realign autonomy expectations with one another (Lichtwarck-Aschoff, Kunnen, \& Van Geert, 2010). Mothers in more emotionally variable dyads might, therefore, be expected to relax control over adolescents over time, thereby gradually allowing adolescents to make decisions without informing them first. Ultimately, in the longer run it is, thus, possible that more emotional variability during conflict interactions in early adolescence is related to changes towards a more horizontal nature of the relationship, with less authority and control of mothers over their adolescents.

\section{Research aims and hypotheses}

Emotional variability of mother-adolescent dyads during conflict interactions is, thus, thought and found to be a key mechanism in dealing with relational challenges and in the development towards more egalitarian mother-adolescent relationships (e.g., Fogel, 1993; Van der Giessen et al., 2013). However, the specific role of emotional variability during conflict interactions for adolescent disclosure and maternal control has not been investigated yet. The major aim of the current study is to examine concurrent and longitudinal associations between observed emotional variability during mother-adolescent conflict interactions in early adolescence and mothers' perceptions of adolescent disclosure and maternal control in early and late adolescence. We expect that higher levels of emotional variability during mother-adolescent conflict interactions in early adolescence are related to higher levels of adolescent disclosure and lower levels of maternal control in early adolescence, and to relative increases in adolescent disclosure and relative decreases in maternal control from early to late adolescence. Although the current study was mainly interested in examining the unique role of emotional variability of mother-adolescent dyads for adolescent disclosure and maternal control, earlier studies have shown that the type of emotional responses expressed was related to adolescent disclosure and maternal control (Marshall et al., 2005; Tilton-Weaver et al., 2010). Therefore, we controlled for the emotional valence (i.e., types of emotions expressed) of the conflict interactions.

\section{Method}

Sample and procedure

Participants were 92 mother-adolescent dyads who were a subsample of the young cohort from the larger longitudinal research project called "RADAR Young" (Research on Adolescent Development And Relationships Young). This is an ongoing longitudinal study in the Netherlands that focuses on the development of relationships and problem behavior in adolescence. For the current study, observation data of mother-adolescent conflict interactions were used from the first (T1) measurement wave, and questionnaire data of mothers were used from the first (T1) and sixth (T6) measurement wave with a 5-year interval. At the first wave, the mean age of the mothers was 44.87 years $(\mathrm{SD}=4.83)$, and the mean age of the adolescents was 13.01 years $(\mathrm{SD}=.52)$. The sample consisted of 54 boys $(58.7 \%)$ and 38 girls $(41.3 \%)$. At the first wave, adolescents were in the first grade of junior high. Most adolescents lived in medium or high socioeconomic status (SES) families (92.4\%), which implies that at least of one the parents' jobs was classified as medium level (e.g., police officer, physician's assistant) or high level (e.g., physician, scientist, high school teacher). The remaining adolescents (5.6\%) lived in families with low SES which means that at least one of the parents was unemployed or held an elementary job (e.g., construction worker, janitor, truck driver). Attrition in the observation sample was $8.7 \%$ from T1 to T6. Attrition analyses revealed no differences in gender, family SES, age, adolescent disclosure at T1, and maternal control at T1 between participants who participated at T1 and T6 and participants that dropped out of the study.

Participants were recruited from several randomly selected Dutch schools in the province of Utrecht, and the cities of Amsterdam, Rotterdam, The Hague, and Almere. Teacher screening and parent interviews were used to select the families in the main RADAR sample $(N=497)$. The participants received written information describing the research project. At the first wave 102 mother-adolescent dyads were randomly selected from the main RADAR-sample to participate in the annual videotaped interactions tasks during home-visits. Ninety-two dyads were willing to participate and provided written informed consent. Families received $€ 100$ per home-visit. This study was approved by the medical ethics committee of the University Medical Center in Utrecht.

\section{Conflict interaction task}

For the conflict interaction task during the home visits, mothers and adolescents were first asked to choose a conflict issue that they discussed most often during the last month. We provided the Interpersonal Conflict Questionnaire (Laursen, 1995), 
which lists topics of frequent family conflicts (e.g., chores, school problems, curfews), as an aid to select topics. Mothers and adolescents had to agree about the topic of their conflict discussion. Next, dyads were instructed by a research assistant to solve the conflict as best as they could within $10 \mathrm{~min}$. These discussions were videotaped. Each conflict interaction task was coded using a simplified version of the Specific AFFect coding system (SPAFF; Gottman, McCoy, Coan, \& Collier, 1996), which has been applied successfully to parent-child interactions (e.g., (Hollenstein, Granic, Stoolmiller, \& Snyder, 2004)). SPAFF identifies the affects expressed during interactions through a combination of verbal content, voice tone, facially expression, and physical cues. Coders categorized the affects displayed using four positive codes (affection, enthusiasm, humor, interest), five negative codes (complaining, sadness, fear, anger, contempt), and a neutral code (refers to statements and information exchanges that are non-emotional in content and voice tone). These 10 affect codes were mutually exclusive. Trained coders entered affect codes in real-time for each mother and adolescent independently using The Observer XT 9.0 (Noldus Information Technology, 2009). For each mother-adolescent conflict interaction, this yielded two synchronized streams of continuous data for mothers and adolescents. Coders were trained intensively over a 3-month period to achieve a minimum inter-observer criterion of 75\% agreement and .65 kappa for the total conflict interaction using an event-unit based comparison with a 3s tolerance window (Bakeman, Quera, \& Gnisci, 2009). To maintain these criteria, weekly discussion meetings were conducted. Twenty percent of the videotaped interactions were independently coded by two coders to provide estimates of reliability. Coders were unaware which sessions were used to assess observer agreement. The average inter-observer agreement at $\mathrm{T} 1$ was $83 \%$ (.73 kappa).

\section{Measures}

\section{Emotional variability}

To capture the emotional variability of mother-adolescent dyads, the data of each conflict interaction were plotted on state space grids in GridWare 1.15a (Lamey, Hollenstein, Lewis, \& Granic, 2004). This program plots the real-time emotions (SPAFF codes) during the conflict interactions on state space grids (see Fig. 1). A grid represents all possible emotional combinations of a dyad, and each cell on the grid represents a potential emotional state of the dyad. For the present study, state space grids consisted of 100 cells, because for each dyad member 10 possible emotions or SPAFF codes were available during the conflict discussions. The mother's coded emotions are plotted on the $x$-axis and the adolescent's emotions are plotted on the $y$-axis. Any time an emotion changes (of either mothers, adolescents, or both), a new point is plotted on the grid and a line is drawn connecting it to the previous point. The arrows denote the changes between emotional states of dyads. The size of the points on the grid represents the amount of time spent in that emotional state; the larger the circle, the longer the duration in that emotional state. A trajectory is plotted through the successive points on the grid in the same order as the emotions proceeds in real time. Hence, a grid represents a sequence of dyadic emotional states.

Two distinct measures of dyadic emotional variability, which have been shown to exhibit good reliability and predictive validity (Granic, O'Hara, Pepler, \& Lewis, 2007; Hollenstein et al., 2004), were derived from GridWare for each mother-

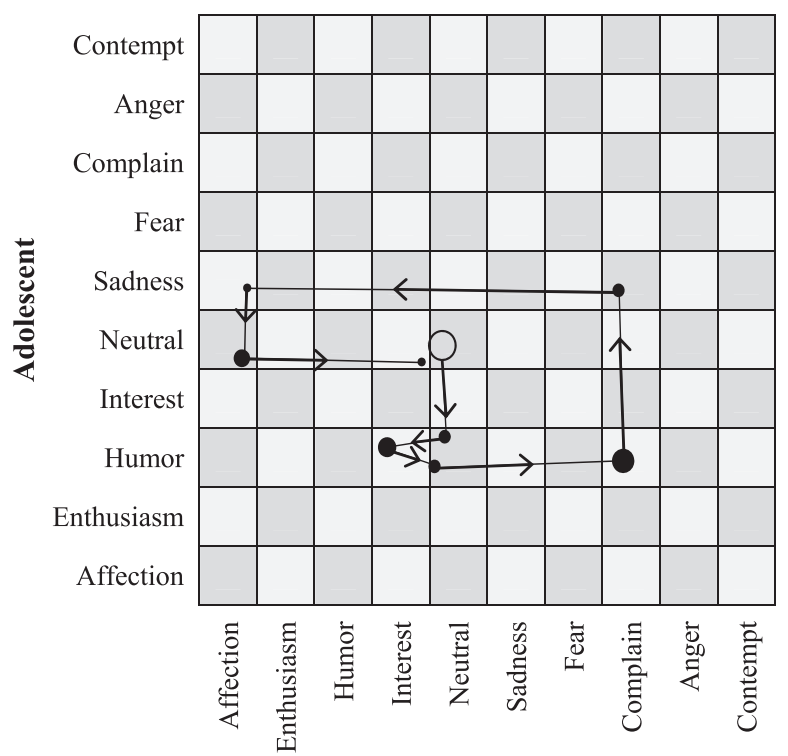

Mother

Fig. 1. An Example of a State Space Grid Depicting a Sequence of Emotions of a Mother-Adolescent Dyad. Note. Each cell on the grid represents a potential dyadic emotion. A trajectory is plotted through the successive points on the grid in the same order as the emotions proceed in real time. The size of the circles is proportional to the duration of time dyads express each emotion and the arrows reflect the changes of dyads between emotions. 
adolescent dyad at the first wave. First, to tap emotional flexibility, transitions per minute assessed the number of dyadic changes or movements per minute between cells on the state space grid, and it was corrected for differences in total duration of the conflict discussions. Higher values indicated more frequent changes per minute between dyadic emotional states ( $M$ $\mathrm{T} 1=5.17, \mathrm{SD}=2.59$ ). Second, to tap the emotional repertoire, dispersion assesses the spread of dyadic emotional states. Dispersion ranges from 0 to 1 , with values close to one indicating that behavior was equally distributed across cells and values of zero indicating that behavior was in only one cell $(M \mathrm{~T} 1=.34$, SD $=.17)$. For each mother-adolescent dyad an emotional variability construct was created, resulting in a measure of general dyadic emotional variability (Hollenstein et al., 2004). Each emotional variability construct combined the Z-scores of transitions and dispersion by computing their mean, thereby reflecting these two different aspects of emotional variability of dyads, namely emotional flexibility and the emotional repertoire. Higher scores indicated higher levels of emotional variability of dyads, that is, these dyads showed the ability to flexibly switch between a broad range of positive and negative emotions.

\section{Emotional affect ratio}

To capture the overall emotional valence of the dyadic conflict interactions, we calculated for each mother-adolescent dyad the emotional affect ratio. Affect ratios have been found to be good predictors of well-being and adjustment in adolescence and adulthood (Fredrickson \& Losada, 2005; Silk et al., 2011). First, we derived from GridWare the total duration in seconds of dyadic positive affect (SPAFF codes affection, enthusiasm, humor, and interest) and dyadic negative affect (SPAFF codes complain, sadness, fear, complain, anger, and contempt) of mother-adolescent dyads. The duration of positive affect and the duration of negative affect of dyads was each corrected for differences in total duration of the interaction ((durationaffect/duration total interaction) ${ }^{*} 100$ ). Second, these corrected measures of dyadic positive and negative affect were used to calculate a dyadic affect ratio. This ratio represents the proportion of positive versus negative affect of a dyad during their interaction (negative affect/(positive affect + negative affect)). Higher scores indicated that dyads showed more negative affect than positive affect during conflict interactions.

\section{Disclosure and control}

To tap mothers' perceptions of adolescent disclosure and maternal control we used two scales developed by Stattin and Kerr (2000), which have demonstrated adequate validity and reliability in previous studies (Racz \& McMahon, 2011). All questions were scored by mothers, using a 5-point Likert scale, ranging from $1=$ never to $5=$ often. Items were averaged to compute mean composite scores. First, the adolescent disclosure scale measured with 6 items adolescents' voluntary and spontaneous revelations about friends, activities, and whereabouts. An example item is 'Does your child spontaneously tell things to you about his/her friends?' ( $\alpha$ s .71 at T1 and .83 at T6). Second, the maternal control scale measured with 5 items the way in which mothers perceive themselves as controlling their adolescent child's activities and friendships. An example of an item is 'Does your child need your permission before he or she can go out during the weeknights?' ( $\alpha$ s .82 at T1 and .87 at T6).

\section{Results}

To examine whether emotional variability was concurrently and longitudinally associated with adolescent disclosure and maternal control, we performed a path analysis in Mplus 6 (Muthén \& Muthén, 2010). The model consisted of observed emotional variability at T1, perceptions of adolescent disclosure at T1, and perceptions of maternal control at T1. Also, we included perceptions of adolescent disclosure and maternal control at T6. Finally, we included the observed emotional affect ratio at $\mathrm{T} 1$ in the analysis, to control for the emotional valence of conflict interactions. With a sample size of 92 and an alpha of $5 \%$ we had a power of .80 to find medium sized effects (Faul, Erdfelder, Lang, \& Buchner, 2007). We used Full Information Maximum Likelihood estimation, because the variables were normally distributed (maximum skewness values -1.10 ) and the Little's MCAR test (1988) produced a normed and nonsignificant $\chi^{2}\left(\chi^{2} / d f\right)$ of 1.17 , which indicated a good fit between sample scores with and without imputation (Bollen, 1989).

\section{Descriptive statistics}

Table 1 provides descriptive statistics and correlations of all study variables. The means in Table 1 revealed that levels of adolescent disclosure and in particular maternal control, decreased over time. Repeated measures ANOVA also showed significant decreases in adolescent disclosure from T1 to T6 $\left(F(1,80)=32.66, p<.001, \eta^{2}=.29\right)$ and especially in maternal control from T1 to T6 $\left(F(1,79)=112.29, p<.001, \eta^{2}=.64\right)$. In addition, the mean of the emotional affect ratio indicated that mother-adolescent dyads showed relative more negative than positive affect during the conflict interactions. The correlations in Table 1 showed, first of all, that more emotional variability was significantly related to relatively more negative than positive affect (emotional affect ratio) during interactions. This indicates that, in line with the definition of emotional variability, more emotionally variable dyads revealed a broad range of both positive and negative emotions. Furthermore, more emotional variability at T1 was significantly associated with more adolescent disclosure at T1 and T6, and with lower maternal control at T6; when mother-adolescent dyads flexibly switched among a broad range of emotions during conflict interactions, mothers reported more disclosure of adolescents regarding leisure activities at T1, and more disclosure and weaker maternal control five years later. The emotional affect ratio at T1 was also positively related to adolescent disclosure at T1, reflecting that when mother-adolescent dyads showed relatively more negative than positive affect during conflict interactions at T1, 
Table 1

Zero-order correlations between emotional variability, the emotional affect ratio, adolescent disclosure, and maternal control.

\begin{tabular}{|c|c|c|c|c|c|c|c|c|}
\hline & $M$ & SD & 1. & 2. & 3. & 4. & 5. & 6. \\
\hline 1. Emotional variability T1 & .00 & .96 & - & & & & & \\
\hline 2. Emotional affect ratio $\mathrm{T} 1$ & 56.31 & 24.66 & $.33^{* *}$ & - & & & & \\
\hline 3. Adolescent disclosure T1 & 4.33 & .50 & $.26^{*}$ & $.25^{*}$ & - & & & \\
\hline 4. Maternal control T1 & 4.51 & .84 & -.06 & -.02 & .15 & - & & \\
\hline 5. Adolescent disclosure T6 & 3.97 & .70 & $.33^{* *}$ & .13 & $.60^{* *}$ & .11 & - & \\
\hline 6. Maternal control T6 & 2.79 & 1.10 & $-.44^{* *}$ & -.15 & -.07 & $.22 *$ & -.12 & - \\
\hline
\end{tabular}

Note. The emotional variability construct combined the $Z$-scores of transitions per minute and dispersion, and therefore the mean score represented here is zero. For the raw mean score of transitions per minute and dispersion, the reader is referred to the description of the measures in the method section on page 10 . ${ }^{*}=p<.05,^{* *}=p<.01$.

mothers reported more disclosure of adolescents at T1. Finally, there were no concurrent and longitudinal associations of maternal control with adolescent disclosure and the emotional affect ratio.

Model results: emotional variability, adolescent disclosure, and maternal control

Fig. 2 provides the standardized estimates of the model examining concurrent and longitudinal associations between observed emotional variability, and perceptions of adolescent disclosure and maternal control, while controlling for the observed emotional affect ratio. The model provided an excellent overall fit to the data: $\chi^{2}(2)=.27, p=.87 ; \mathrm{CFI}=1.00$; RMSEA $=.00$, range $.00-10$. In early adolescence emotional variability was positively associated with the control variable emotional affect ratio: More emotionally variable dyads showed relatively more negative than positive affect during the conflict interactions. Also, the emotional affect ratio at T1 was positively related to adolescent disclosure at $\mathrm{T} 1$, indicating that when mother-adolescent dyads showed more negative than positive affect during conflict interactions at T1, mothers perceived more disclosure of adolescents at T1. Yet, the emotional affect ratio at T1 was not related to maternal control at T1. Finally, maternal control and adolescent disclosure were not concurrently associated, neither at T1 nor at T6.

Adolescent disclosure at $\mathrm{T} 1$ was positively associated with emotional variability at $\mathrm{T} 1$. This suggests that when motheradolescent dyads showed more emotional variability during conflict interactions at T1, mothers perceived higher levels of adolescent disclosure at T1. This was consistent with our expectations. However, emotional variability at T1 did not predict relative changes in adolescent disclosure from $\mathrm{T} 1$ to T6. This indicated that emotional variability of mother-adolescent dyads

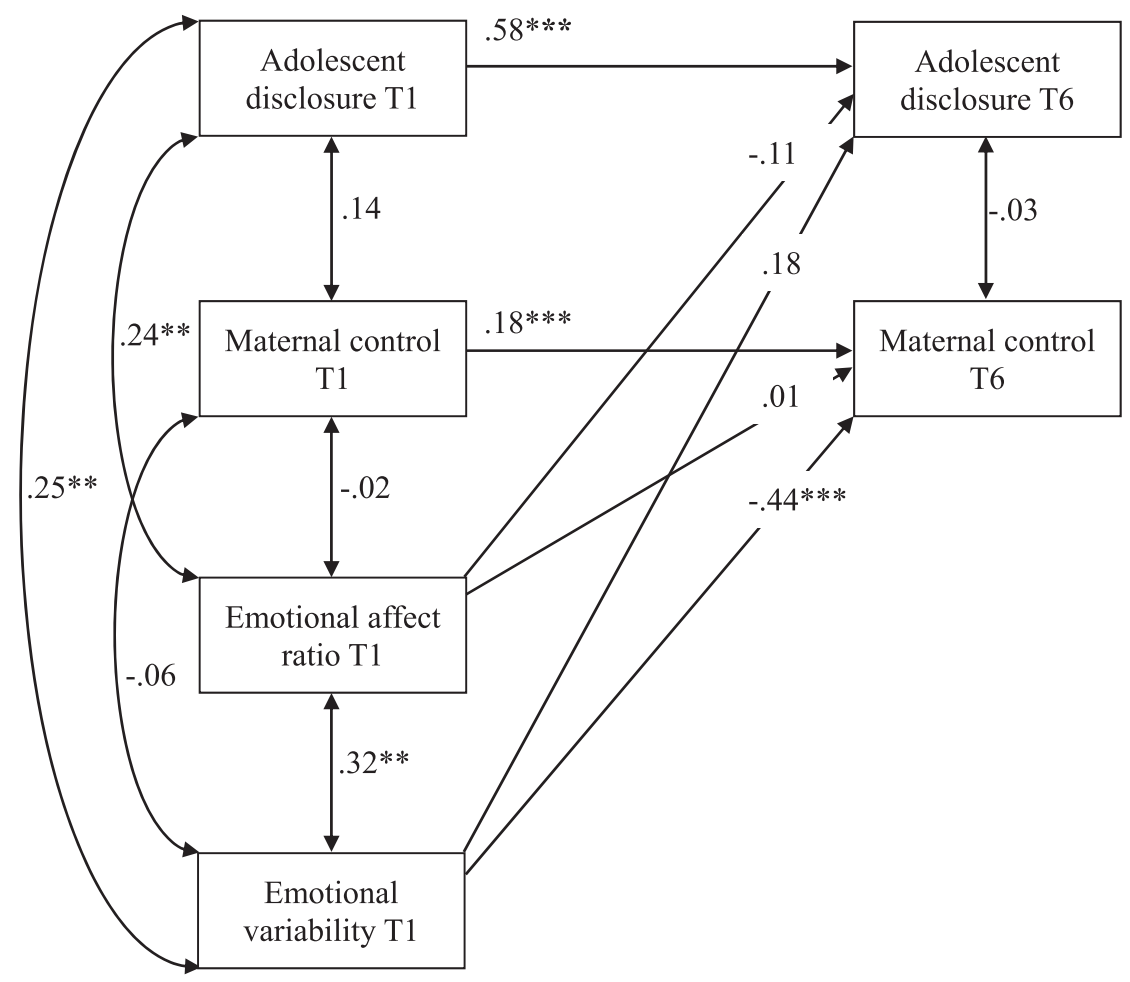

Fig. 2. Standardized parameter estimates for the concurrent and longitudinal associations between emotional variability, adolescent disclosure, and maternal control, while controlling for the emotional affect ratio. ${ }^{* *}=p<.01,^{* * *}=p<.001$. 
at T1 was not associated with adolescent disclosure at T6, when controlling for its association with adolescent disclosure at T1. In line with this, adolescent disclosure showed considerable stability over 5 years.

Maternal control at T1 was not associated with emotional variability at T1. However, emotional variability at T1 predicted, as expected, a relative decrease in maternal control from $\mathrm{T} 1$ to $\mathrm{T} 6$. When mother-adolescent dyads showed more emotional variability at T1, mothers reported a relative stronger decrease in their control over the period from T1 to T6. The longitudinal association of emotional variability with maternal control was of considerable strength, also considering that we controlled for previous levels of maternal control, adolescent disclosure, and the emotional affect ratio.

\section{Discussion}

The aim of this study was to examine associations between emotional variability of mother-adolescent dyads observed during conflict interactions in early adolescence and mothers' perceptions of adolescent disclosure and maternal control in early and late adolescence. Results supported our hypothesis from a dynamic systems perspective (e.g., Branje, 2008; Fogel, 1993; Van der Giessen et al., 2013) that more emotional variability in mother-adolescent conflict interactions is helpful in adaptively dealing with relational challenges that arise during adolescence. More emotional variability in early adolescence was associated with (a) higher levels of adolescent disclosure in early adolescence, and (b) relative decreases in levels of maternal control from early to late adolescence.

Emotional variability in conflict interactions in early adolescence was only associated with adolescent disclosure in early adolescence. As expected, when mother-adolescent dyads were more able to flexibly switch among abroad range of positive and negative emotions during conflict interactions in early adolescence, mothers perceived adolescents to generally disclose more information about their friends, activities, and whereabouts to them. This result supports the idea that more emotional variability during conflict interactions is a potential indicator of more open communication and a context which is accepting of both positive and negative emotions (e.g., Branje, 2008; Granic, Dishion, \& Hollenstein, 2006). More open communication and mutual understanding is important for adequately handling conflict interactions during adolescence (Adams \& Laursen, 2007; Petronio, 2002). Adolescent disclosure seems to be facilitated when mother-adolescent dyads more openly and flexibly express emotions towards each other during conflict interactions.

Current findings puts some nuances to earlier studies which have shown that more conflicts between mothers and adolescents and that more negative emotional responses of mothers were related to fewer disclosures of adolescents (e.g., Marshall et al., 2005; Tilton-Weaver et al., 2010). Yet, when mother-adolescent dyads are able to flexibly express all of their emotions, both positive and negative, within conflict interactions, this could be indicative of a safe and supportive interaction context, and adolescents might therefore also feel free to discuss everyday issues with their mothers indicating higher levels of disclosure (Adams \& Laursen, 2007; Keijsers, Frijns, Branje, \& Meeus, 2009). In fact, our results also showed that when dyads were observed to let out relatively more negative than positive emotions during conflict interactions, adolescents were also perceived by mothers to open up about their leisure time. Earlier studies examining inter-individual differences in adolescent disclosure predominantly focused on adolescents' general perceptions of negative or positive responses of mothers (e.g., Tilton-Weaver et al., 2010). Yet, the current study elicited real-time emotions of mother-adolescent dyads during conflicts. As such, relatively more negative than positive emotions during these conflicts might not be perceived by adolescents as potentially conflictual or negative, and therefore these adolescents perhaps do not feel discouraged to disclose information to their mothers. Taken together, during early adolescence conflict interactions should be a context in which mother-adolescent dyads can safely and easily express both positive and negative emotions (e.g., Van der Giessen et al., 2013), and such conflict interactions might facilitate adolescents' disclosure of information to mothers.

In contrast with our expectations and the considerable correlation coefficient, results revealed that emotional variability in early adolescence did not predict adolescent disclosure in late adolescence, when controlling for disclosure in early adolescence. This result might be explained by the considerable stability of adolescent disclosure from early to late adolescence, which suggests that more emotional variability of mother-adolescent dyads is related to stable levels of adolescent disclosure, and may therefore reflect relatively stable open communication patterns of dyads. Current results might also reflect that emotional variability during conflict interactions does not necessarily facilitate changes in affective qualities (i.e., disclosure) of mother-adolescent relationships. Adolescents are active agents in sharing information with mothers (Branje et al., 2012), and changes in adolescent disclosure might be driven more by adolescents than by motheradolescent dyads. Instead emotional processes of dyads during conflict interactions seem to enable the reorganization of the power dynamics in mother-adolescent relationships.

Furthermore, although as expected more emotional variability in early adolescence predicted relative decreases of maternal control from early to late adolescence, emotional variability was, in contrast with our expectations, not concurrently associated with maternal control in early adolescence. These findings suggest that more emotional variability during conflict

\footnotetext{
${ }^{1}$ We checked whether results were the same when controlling for the duration of positive affect and negative affect separately (instead of controlling for the emotional affect ratio). Similar results were obtained. More emotional variability of dyads was significantly related to more negative affect and more positive affect during the conflict interactions in early adolescence, indicating that more emotionally variable dyads indeed flexibly switch among both positive and negative emotions. Thus, in order to reduce the number of variables in our analysis we decided to include the emotional affect ratio in the model.
} 
interactions enables mothers to gradually relax control over time and may actually push the relationship towards a more horizontal distribution of power by the end of adolescence. This fits with the assumptions of a dynamic systems approach (e.g., Fogel, 1993; Lichtwarck-Aschoff et al., 2009) that more emotional variability allows for relationship transformations to take place. A great deal of studies, as well as the current study, has shown that mothers tend to relax control from middle adolescence onwards (e.g., Bosma et al., 1996; Keijsers \& Poulin, 2013). Relatively higher levels of maternal control are considered to be normative in early adolescence (Eccles et al., 1991; Smetana, 2011), which might explain the non-significant relation between emotional variability and maternal control in early adolescence. Yet, in order to support adolescents' increasing need for autonomy, mothers need to increasingly allow adolescents to make decisions without informing their mothers first (Branje et al., 2012; Steinberg, 2001). Mothers, however, can vary in their willingness or ability to let go of their control over adolescents. As such, more emotional variability might characterize mother-adolescent dyads who exchange discordant thoughts, expectations, and arguments during conflict interactions, which might result in adequately negotiating adolescents' autonomy, and in mothers exerting less control by late adolescents. Taken together, our findings suggest that relative decreases in maternal control from early to late adolescence is facilitated through flexibly expressing a broad range of positive and negative emotions during conflict interactions in early adolescence.

\section{Strengths, limitations, and future directions}

Although the current study has a number of important strengths, such as the longitudinal and multi-method design as well as the examination of real-time emotions of mother-adolescent dyads, several limitations should also be noted and addressed in future research. First, the current study investigated emotional variability during conflict interactions, because conflict interactions are considered to play an important role in reorganization mother-adolescent relationships during adolescence (Adams \& Laursen, 2007; Lichtwarck-Aschoff et al., 2010). Yet, mother-adolescent dyads also face different and increasingly complex interpersonal contexts, and emotional demands are distinct across these contexts (Collins \& Steinberg, 2006). Future research could, therefore, address whether emotional variability in other interaction contexts is also a marker of more adolescent disclosure and predictive of less maternal control. Second, the current data were gathered from a relatively homogeneous sample of Caucasian mothers and adolescents from relatively high SES families. The current findings should be replicated with more ethnically and economically diverse samples. Third, reports of mothers on adolescents were used. This excluded the possibility to examine associations between emotional variability of mother-adolescent dyads and adolescent reports of control and disclosure. Using adolescent accounts of these behaviors may provide a different view on these processes. Fourth, the data used in the current study did not allow us to examine the developmental order between emotional variability and both adolescent disclosure and maternal control, and we were, thus, not able to infer the directional order of these associations. Future research could investigate whether emotional variability predicts subsequent levels of adolescent disclosure and maternal control, or whether adolescent disclosure and maternal control predict subsequent levels of emotional variability.

\section{Conclusion}

Notwithstanding these limitations, the present study advances our understanding of the role of emotional variability in mother-adolescent interactions in early adolescence for adolescent disclosure and maternal control over the course of adolescence. This study clearly demonstrates that more emotional variability during conflict interactions in early adolescence is associated with higher levels of adolescent disclosure in early adolescence as well as with relative decreases of maternal control from early to late adolescence. More emotional variability of mother-adolescent dyads during conflict interactions might reflect more open communication patterns of these dyads, which may allow adolescents to disclose information about leisure time activities and which may enable mothers to gradually relax control over time. Current results can help mother-adolescent dyads to understand how to adapt dyadic interaction patterns during conflict interactions in order to cope with developmental changes that take place during adolescence. Although it is often thought that negative emotions should be suppressed and positive emotions should be encouraged during mother-adolescent interactions, this study shows that in early adolescence it is more desirable for dyads to flexibly express a broad range of both negative and positive emotions during conflict interactions. Preventions efforts should therefore focus on educating mother-adolescent dyads about the importance of expressing, sharing, modulating and shifting out of a wide variety of positive and negative emotions during conflict interactions.

\section{Acknowledgments}

Data of the RADAR study were used. RADAR has been financially supported by main grants from the Netherlands Organisation for Scientific Research (GB-MAGW 480-03-005), and Stichting Achmea Slachtoffer en Samenleving (SASS), and various other grants from the Netherlands Organisation for Scientific Research, the VU University of Amsterdam and Utrecht University.

\section{References}

Adams, R. E., \& Laursen, B. (2007). The correlates of conflict: disagreement is not necessarily detrimental. Journal of Family Psychology, 21, 445-458. http:// dx.doi.org/10.1037/0893-3200.21.3.445. 
Bakeman, R., Quera, V., \& Gnisci, A. (2009). Observer agreement for timed-event sequential data: a comparison of time-based and event-based algorithms. Behavior Research Methods, 41, 137-147. http://dx.doi.org/10.3758/BRM.41.1.137.

Bollen, K. A. (1989). Structural equation models with latent variables. New York: Wiley.

Bosma, H. A., Jackson, S. E., Zijsling, D. H., Zani, B., Cicognani, E., Lucia Xerri, M., et al. (1996). Who has the final say? Decisions on adolescent behaviour within the family. Journal of Adolescence, 19, 277-291. http://dx.doi.org/10.1006/jado.1996.0025.

Branje, S. J. T. (2008). Conflict management in mother-daughter interactions in early adolescence. Behaviour, 145, 1627-1651. http://dx.doi.org/10.1163/ 156853908786131315.

Branje, S., Laursen, B., \& Collins, W. A. (2012). Parent-child communication during adolescence. In A. Vangelisti (Ed.), Routledge handbook of family communication (2nd ed.). (pp. 271-286) New York: Routledge.

Butler, E. A. (2011). Temporal interpersonal emotion systems: the "TIES" that form relationships. Personality and Social Psychology Review, 15, 367-393. http://dx.doi.org/10.1177/1088868311411164.

Collins, W. A., \& Steinberg, L. (2006). Adolescent development in interpersonal context. In N. Eisenberg, W. Damon, \& R. Lerner (Eds.), Social, emotional and personality development: Vol. 3. Handbook of child psychology (pp. 1003-1067). Hoboken New Jersey: John Wiley \& Sons., Inc.

Eccles, J. S., Buchanan, C. M., Flanagan, C., Fuligni, A., Midgley, C., \& Yee, D. (1991). Control versus autonomy during early adolescence. Journal of Social Issues, 47, 53-68. http://dx.doi.org/10.1111/j.1540-4560.1991.tb01834.x.

Faul, F., Erdfelder, E., Lang, A., \& Buchner, A. (2007). G*power 3: a flexible statistical power analysis program for the social, behavioral, and biomedical sciences. Behavior Research Methods, 39, 175-191. http://dx.doi.org/10.3758/BF03193146.

Fogel, A. (1993). Developing through relationships: Origins of communication, self, and culture. Chicago, IL: University of Chicago Press.

Fredrickson, B. L., \& Losada, M. F. (2005). Positive affect and the complex dynamics of human flourishing. American Psychologist, 60, 678-686. http://dx.doi. $\operatorname{org} / 10.1037 / 0003-066 X .60 .7 .678$.

Gottman, J., McCoy, K., Coan, J., \& Collier, H. (1996). The SPecific AFFect coding system (SPAFF) for observing emotional communication in marital and family interaction. Mahwah, NJ: Erlbaum.

Granic, I., Dishion, T. J., \& Hollenstein, T. (2006). The family ecology of adolescence: a dynamic systems perspective on normative development. In G. R. Adams, \& M. D. Berzonsky (Eds.), Blackwell handbook of adolescence (pp. 60-91). Blackwell Publishing Ltd.

Granic, I., O'Hara, A., Pepler, D., \& Lewis, M. D. (2007). A dynamic systems analysis of parent-child changes associated with successful "real-world” interventions for aggressive children. Journal of Abnormal Child Psychology, 35, 845-857. http://dx.doi.org/10.1007/s10802-007-9133-4.

Hawk, S. T., Hale, W. W., Raaijmakers, Q. A. W., \& Meeus, W. (2008). Adolescents' perceptions of privacy invasion in reaction to parental solicitation and control. The Journal of Early Adolescence, 28, 583-608. http://dx.doi.org/10.1177/0272431608317611.

Hollenstein, T. (2012). State space grids. Depicting dynamics across development. New York: Springerhttp://dx.doi.org/10.1007/978-1-4614-5007-8.

Hollenstein, T., Granic, I., Stoolmiller, M., \& Snyder, J. (2004). Rigidity in parent-child interactions and the development of externalizing and internalizing behavior in early childhood. Journal of Abnormal Child Psychology, 32, 595-607. http://dx.doi.org/10.1023/B: JACP.0000047209.37650.41.

Keijsers, L., Frijns, T., Branje, S. J. T., \& Meeus, W. (2009). Developmental links of adolescent disclosure, parental solicitation, and control with delinquency: moderation by parental support. Developmental Psychology, 45, 1314-1327. http://dx.doi.org/10.1037/a0016693.

Keijsers, L., \& Poulin, F. (2013). Developmental changes in parent-child communication throughout adolescence. Developmental Psychology. http://dx.doi. $\operatorname{org} / 10.1037 / \mathrm{a} 0032217$

Lamey, A., Hollenstein, T., Lewis, M., \& Granic, I. (2004). GridWare (version 1.15a). [Computer software]. Retrieved from http://www.Statespacegrids.Org.

Laursen, B. (1995). Conflict and social interaction in adolescent relationships. Journal of Research on Adolescence, 5, 55-70. http://dx.doi.org/10.1207/ s15327795jra05013.

Laursen, B., \& Collins, W. A. (2009). Parent-child relationships during adolescence. In R. M. Lerner, \& L. D. Steinberg (Eds.), Contextual influences on adolescent development: Vol. 2. Handbook of adolescent psychology (pp. 3-42). Hoboken New Jersey: John Wiley \& Sons., Inc.

Laursen, B., Coy, K. C., \& Collins, W. A. (1998). Reconsidering changes in parent-child conflict across adolescence: a meta-analysis. Child Development, 69, 817-832. http://dx.doi.org/10.1111/j.1467-8624.1998.tb06245.x.

Lichtwarck-Aschoff, A., Kunnen, S. E., \& van Geert, P. L. C. (2009). Here we go again: a dynamic systems perspective on emotional rigidity across parentadolescent conflicts. Developmental Psychology, 45, 1364-1375. http://dx.doi.org/10.1037/a0016713.

Lichtwarck-Aschoff, A., Kunnen, S., \& Van Geert, P. (2010). Adolescent girls' perceptions of daily conflicts with their mothers: within-conflict sequences and their relationship to autonomy. Journal of Adolescent Research, 25, 527-556. http://dx.doi.org/10.1177/0743558410367953.

Little, R. J. A. (1988). A test of missing completely at random for multivariate data with missing values. Journal of the American Statistical Association, 83, 1198-1202. http://dx.doi.org/10.2307/2290157.

Marshall, S. K., Tilton-Weaver, L. C., \& Bosdet, L. (2005). Information management: considering adolescents' regulation of parental knowledge. Journal of Adolescence, 28, 633-647. http://dx.doi.org/10.1016/j.adolescence.2005.08.008.

Morris, A. S., Silk, J. S., Steinberg, L., Myers, S. S., \& Robinson, L. R. (2007). The role of the family context in the development of emotion regulation. Social Development, 16, 361-388. http://dx.doi.org/10.1111/j.1467-9507.2007.00389.x.

Muthén, B., \& Muthén, L. (2010). Mplus. Version 6.00 [computer software]. Los Angeles, CA: Muthén \& Muthén.

Noldus Information Technology. (2009). The observer XT 9.0 [computer software]. Wageningen: Noldus Information Technology.

Petronio, S. (2002). Boundaries of privacy. Dialectics of disclosure. Albany, NY: New York press.

Racz, S. J., \& McMahon, R. J. (2011). The relationship between parental knowledge and monitoring and child and adolescent conduct problems: a 10-year update. Clinical Child and Family Psychology Review, 14, 377-398. http://dx.doi.org/10.1007/s10567-011-0099-y.

Silk, J. S., Forbes, E. E., Whalen, D. J., Jakubcak, J. L., Thompson, W. K., Ryan, N. D., et al. (2011). Daily emotional dynamics in depressed youth: a cell phone ecological momentary assessment study. Journal of Experimental Child Psychology, 110, 241-257. http://dx.doi.org/10.1016/j.jecp.2010.10.007.

Smetana, J. G. (2011). Adolescents, families, and social development: How teens construct their worlds. West Sussex, UK: Wiley-Blackwell.

Stattin, H., \& Kerr, M. (2000). Parental monitoring: a reinterpretation. Child Development, 71, 1072-1085. http://dx.doi.org/10.1111/1467-8624.00210.

Steinberg, L. (2001). We know some things: parent-adolescent relationships in retrospect and prospect. Journal of Research on Adolescence, 11, 1-19. http:// dx.doi.org/10.1111/1532-7795.00001.

Thelen, E., \& Smith, L. B. (1994). A dynamic systems approach to the development of cognition and action. Cambridge, MA: Bradford/MIT Press.

Tilton-Weaver, L., Kerr, M., Pakalniskeine, V., Tokic, A., Salihovic, S., \& Stattin, H. (2010). Open up or close down: how do parental reactions affect youth information management? Journal of Adolescence, 33, 333-346. http://dx.doi.org/10.1016/j.adolescence.2009.07.011.

Van der Giessen, D., Branje, S. J. T., Frijns, T., \& Meeus, W. H. J. (2013). Dyadic variability in mother-adolescent interactions: developmental trajectories and associations with psychosocial functioning. Journal of Youth and Adolescence, 42, 96-108. http://dx.doi.org/10.1007/s10964-012-9790-7.

Zimmer-Gembeck, M. J., \& Collins, W. A. (2006). Autonomy development during adolescence. In G. Adams, \& M. Berzonsky (Eds.), Blackwell handbook of adolescence (pp. 175-204). Blackwell Publishing Ltd. 